\title{
DRY SLAG GRANULATION WITH HEAT RECOVERY*
}

Ian James McDonald ${ }^{1}$ Andrea Werner ${ }^{2}$

\begin{abstract}
Each year, approximately 400 million tons of blast furnace slag is produced worldwide with a tapping temperature of around $1,500^{\circ} \mathrm{C}$. It is normally used as a substitute for cement clinker or as an aggregate material in road construction. Currently, the slag is granulated in wet-granulation plants using large volumes of water and to date, it has not been possible to utilise the remnant heat energy of the molten slag, which amounts to approximately $1.8 \mathrm{GJ}$ of energy per ton. However, in an R\&D project currently underway led by Primetals Technolgies and industrial partners, a new dry atomising technology is being investigated to use air to cool molten slag and recover the lost heat energy. The resultant pelletised slag fulfils the same criteria as wet-granulated slag for use in the cement industry. Phase 1 of the project has now been completed where a technical plant was set up at the University of Leoben in 2012. A series of dry-slag granulation campaigns were carried out using remelted blast furnace slag. The elevated offgas temperatures and the quality of the slag product as verified by the FEhS Building Material Institute have shown the process suitability as an industrial application and the decision was taken to escalate the project from large laboratory scale to a full size pilot plant. The phase 2 development of this plant is now underway and is scheduled for installation at the site of an industrial partner in early 2016 where full slag flow will be fed directly to the plant from Blast Furnace 'slag runners. This paper will show the development path taken to date and the planned route to our goal in 2016 of being the first to industrialise the 'game changing' process of dry Slag Granulation with Heat Recovery from the slag.
\end{abstract}

Keywords: Blast furnace; Dry slag granulation; Energy recovery; Cement.

1 Blast Furnace Innovation Manager, Primetals Technologies, Stockton-on-Tees, United Kingdom.

2 Process Engineer - Technology Energy Efficiency and Recycling, Primetals Technologies, Turmstraße 44, Linz, Austria. 


\section{INTRODUCTION}

Each year approximately 400 million tons of blast furnace slag are produced worldwide. The slag, which has a tapping temperature of around $1,500^{\circ} \mathrm{C}$, is normally used as a substitute for cement clinker or as an aggregate material in road construction. The current state-of-the-art practice is to granulate molten blast furnace slag in wet-granulation plants using large volumes of water. However, up until now it has not been possible to utilize the remnant heat energy of the molten slag, which amounts to approximately $1.8 \mathrm{GJ}$ of energy per ton of slag.

In an R\&D project currently underway by a consortium of companies led by Primetals Technologies (UK and Austria) and comprising Voestalpine Stahl GmbH (Austria), FEhS Building Materials Institute (Germany) and the University of Leoben (Austria), a new technology based on dry-slag-granulation is being investigated to use air to cool molten slag and to recover the remnant heat energy for heating applications or for the generation of electrical energy. At the same time, the slag product should also fulfill the same criteria as wet-granulated slag for use in the cement industry.

The project was officially launched on September 1, 2011. A technical plant was set up at the University of Leoben in Austria where in the summer of 2012 through 2013, a series of dry-slag granulation campaigns were carried out using remelted blast furnace slag. The quality of the granulated slag produced and the elevated offgas temperatures made during the trials were highly promising and helped determine the process boundaries and provide the basis for a larger site based plant.

The results from the campaigns were used to calibrate calculation models of the granulator (e.g. a 3-D CFD model) as the basis for the upscaling of the technical plant design to an industrial scale pilot plant. The pilot plant is to be erected on the site of our industrial partner to investigate the dry slag granulation process in an industrial scale iron and steelmaking environment.

The development of this plant is now underway and is scheduled for installation in 2016.

\subsection{Substitution of Cement Clinker with Slag Sand}

Traditional manufacturing of cement clinker from limestone, sand, clay and other components requires a high-temperature process (around $1450^{\circ} \mathrm{C}$ ). It is also associated with high demand for raw materials, high input of primary energy and high specific $\mathrm{CO} 2$ emissions (roughly $1 \mathrm{t}$ of $\mathrm{CO} 2$ per ton of clinker). The substitution of cement clinker by blast furnace slag sand is an attractive economic alternative for the cement industry, because it reduces high energy costs and considerably improves the company's $\mathrm{CO} 2$

balance. Approximately 1 ton of $\mathrm{CO} 2$ can be saved for each tonne of clinker substituted by slag sand because not only primary energy is saved, but also the release of the carbon dioxide chemically bound in the limestone is avoided.

\section{WET GRANULATION}

\subsection{Conventional Granulation Technique for the Production of Slag Sand}

In this case the slag is quickly "quenched" in granulation plants using large quantities of water, producing a fine-grained, amorphous but also wet product, known as slag sand. Due to the "frozen" crystallization energy, the slag sand when ground to 
cement fines, form hydration products in conjunction with water (latent hydraulic behaviour). These products essentially correspond to the hydration products of Portland cement clinker, the main component of Portland cement. The key prerequisite for the use of slag sand as a binding agent in the building material industry is thus satisfied.

Therefore approximately $80 \%$ of blast furnace slag sand is used as cement additive and realises valuable revenue rather than being disposed of as land-fill.

The wet granulation process operates with a high water to slag ratio of about 8:1.

This wet process is quite accepting to fluctuations in the quantity and properties of the slag, however the wet process has the following drawbacks:

- Despite mechanical dewatering in drums, silos or heaps, a residual moisture of about $10-12 \%$ moisture remains in the slag sand. For the manufacturing of cement, the product therefore first has to be re-dried, with high energy expenditure.

- Assuming $10 \%$ residual moisture, the required drying energy amounts to around $132 \mathrm{kWh} / \mathrm{t}$.

- For granulation with open water circuits, vapour containing sulphur can be released, and a correspondingly large amount of fresh water (about $1 \mathrm{~m}^{3} / \mathrm{t}$ ) has to be fed into the system. Granulation plants with closed water circuits and condensation systems can prevent the emission of water vapour containing sulphur.

- When slag is quenched with water, the high energy potential of liquid slag is wasted to heat and evaporate water. For granulation, the circulated water has to be re-cooled in cooling towers or with other cooling methods. Mainly cooling towers are equipped with electrically operated fans and also the cooling water circulation system consumes a high portion of electrical energy. Finally the heat is released to the environment at a low temperature level without being used.

\section{DRY GRANULATION}

\subsection{Alternative Technique for Producing Vitreous Blast Furnace Slag}

Huge amounts of water and of drying energy can be avoided by dry dispersion and quick cooling of the liquid slag. The essential prerequisite for the introduction of an alternative dry technique is that the obtained product needs identical or even better properties compared to the slag sand produced conventionally using wet granulation. This applies in particular to the glass content (target > 95\%), which is a key parameter for the reactivity and hence the quality of the slag sand.

The glass content has a direct impact on the strength of the cements and concretes. However, the required glass content can only be achieved by sudden cooling below the transformation temperature of approximately $900^{\circ} \mathrm{C}$. Due to the less efficient cooling mechanism of water-free quenching, the dry process is technically more challenging than conventional water based granulation.

Obviously "dry" granulation requires no subsequent drying of the product. This leads to a $\mathrm{CO} 2$ reduction of roughly $30 \mathrm{~kg} / \mathrm{t}$ in comparison with wet process. Given global production of approximately 210 million $t$ of slag sand (2007), this is equivalent to a potential $\mathrm{CO} 2$ reduction of over 6.3 million t per year.

There are two methods in which slag can be fed to any slag granulation plant. The first involves a granulator which is located close to the furnace and enables the slag to be delivered to the plant direct from the slag runner. The second is a system 
remote from the furnace involving the transfer of slag via slag pots and pouring the slag into a granulator via a ladle tilter.

The first module of the DSG process can offer a very simple low cost option for slag disposal with only a spinning cup and slag runner being present. The granules can be roughly strewn by the cup and gathered using a loader after each tapping. There would be no possibility for heat recovery using this simple method, but a cement grade granulate can still be produced.

The second and more practical solution bearing in mind the normal lack of space available around a blast furnace is to confine the atomising granulate inside a vessel. Cooling air is required at this point which leads to the opportunity of waste heat recovery through the increased off gas air temperature.

\subsection{The Concept}

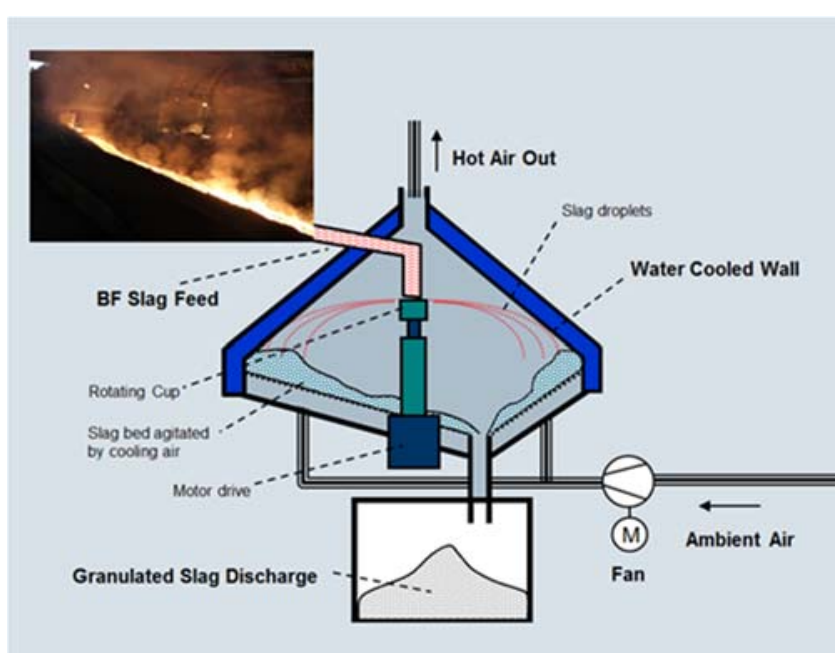

Figure 1. Dry Granulation Concept.

Dry slag granulation is based on molten slag atomisation using a variable speed rotating cup or dish (see Figure 1). The slag is delivered on to the centre of the cup from a slag runner via a vertical refractory lined pipe. The rotation of the cup forces the slag outwards to the cup lip where it is atomised (see Figure 2). Simulation and calculation of the rotating cup gives as a result a suitable cup design with it's main design parameter, the diameter of the cup and required rotational speed. The speed of the cup will be varied according to the current slag flow for a consistently product quality (grain size distribution...) and process stability. .

he atomized particles, mainly in a grain size of 1 to $6 \mathrm{~mm}$ impact on a inclined water cooled wall, bounces off the wall and falls into a bed of granules. A large part of the heat transfer takes place in this flight phase of the particles. A first particle cooling effect is caused by the convection heat transfer to the cooling air and the radiation heat transfer mainly to the cool surface of the water cooled wall. But also during the impact phase of the particles at the water cooled wall a considerable part of heat loss of the particles takes places by heat conductance.

Small sized particles have already created a solid surface before impacting the water cooled wall and bounce directly off the water cooled wall without deformation. Larger sized particles cannot create a stable solid crust on the particle furnaces during their first flight phase. They deform by impacting the wall to a flat form, but they create again a spherical shape during bouncing off the wall because of the physical 
properties of blast furnace slag. The correct angle, quality of the impact surface and the cold surface temperature of the water cooled wall prevent sticking effects of the slag particles at the wall.

The solidifying granules fall into a bed of granules that is designed to ensure that there is no agglomeration. The bed is kept in motion by the design of the cooling air distributor. Several air distribution lines feed cooling air into the granule bed creating a high heat exchange rate between the granulate and the cooling air to discharge cold slag granulate from the granulator whilst harvesting the energy by producing hot air.

The discharging system at the bottom is designed for independent discharge at several different sections of the granulator to a conveyor system. This creates the possibility to even the granulate bed surface for a homogenized bed thickness with the discharging system in the granulator. Also cooling air can pass the discharging modules to have a direct bottom up flow of the cooling air in the granulate bed (counter flow principal).

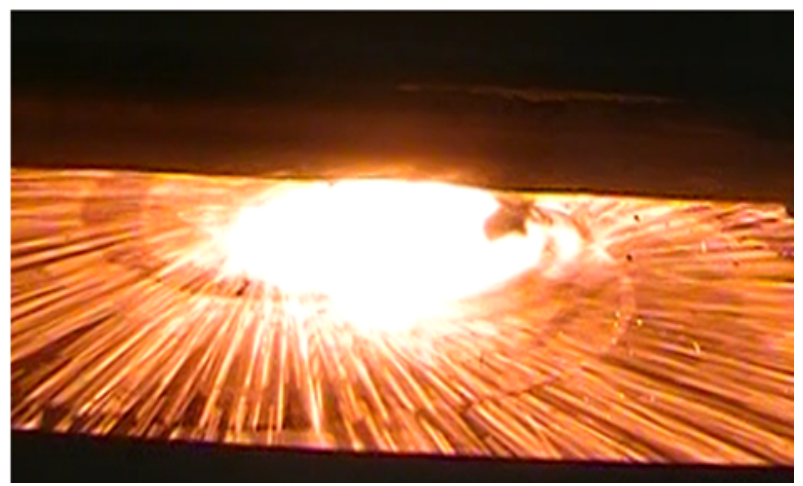

Figure 2. Atomising Slag.

\subsection{The Current R\&D Focus by Primetals Technologies on the Subject of DSG}

With environmental and energy saving considerations becoming ever more important and even becoming enshrined in legislation, there is clearly a need for a major improvement in slag handling.

Our past experience of the dry granulation process is being further enhanced with heat recovery technology to satisfy this requirement and the topic is now a major R\&D project at Primetals Technologies in conjunction with industrial partners.

A site has been chosen to build a new industrial size dry slag granulation pilot plant which will be capable of handling full slag flow from a single taphole in STEP 1 . This STEP will assess and improve process performance and evaluate detailed off gas parameter information for a subsequent heat recovery plant installation. It is the intention to upgrade the facility in a STEP 2 development to include slag flow and full heat recovery from multiple tapholes on the furnace. A view at the development of the STEP 1 granulation plant is shown in Figure 3. 


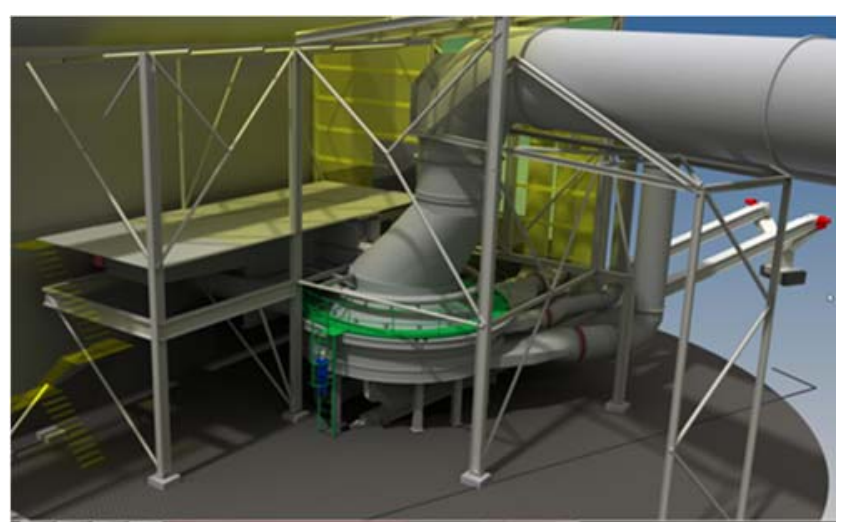

Figure 3. View at STEP 1 granulation plant.

The process of atomising slag using a spinning cup has been suitably proven by Primetals (formerly Davy and Kvaerner) over the years and it is known the granulate produced by this method at over $95 \%$ glassy is suitable for use in the cement industry.

The challenge and focus for us now is to produce the same granulate at air temperatures which are high enough to make the process suitable for waste heat recovery.

Trials have now been completed on a technical granulation plant located at the University of Leoben in Austria (see Figure 4). The results gained have been very encouraging and have matched the CFD calculations for product size and offtake temperatures made at the beginning of the project (see Figure 5).

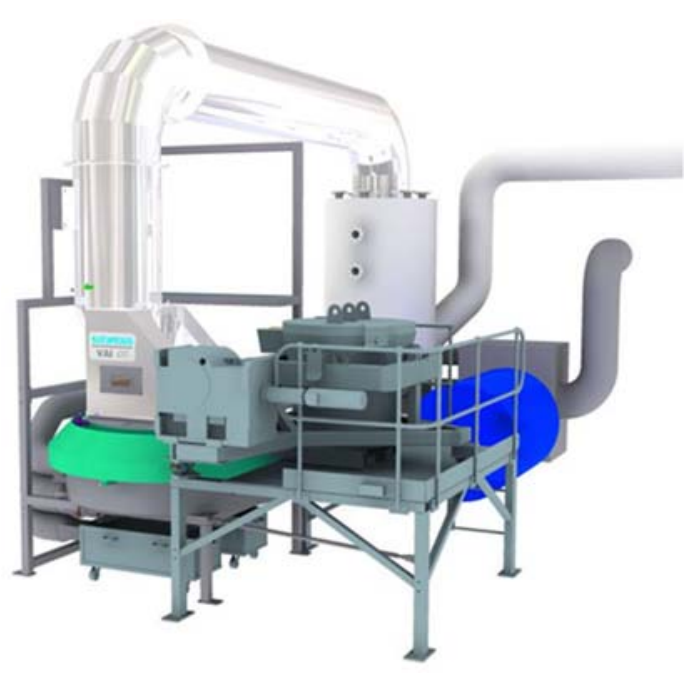

Figure 4. Technical Granulation Plant at Leoben.

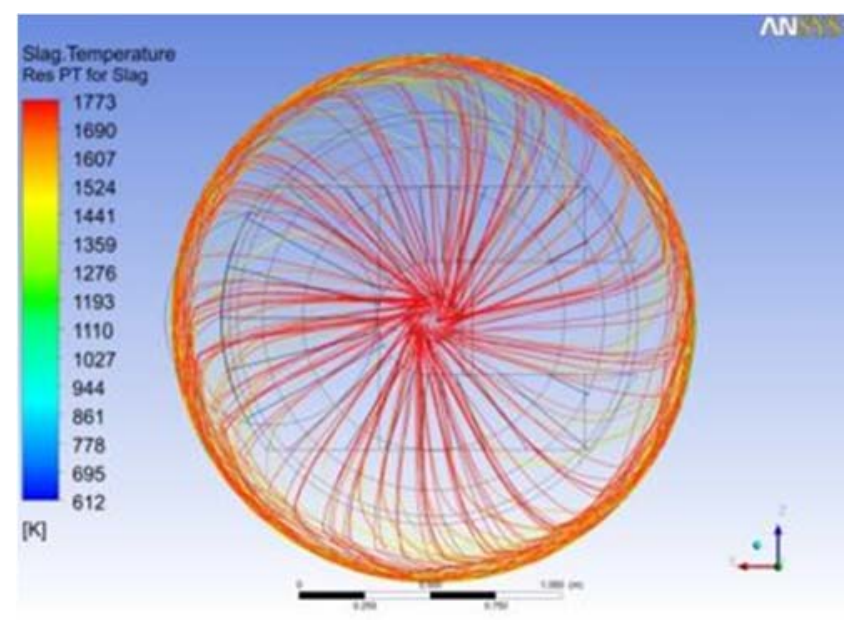

Figure 5. CFD Model Showing Granular Flight and Temperature.

\section{RESULTS FROM LEOBEN TRIALS}

\subsection{Chemical and Mechanical Properties}

Blast furnace slag is considered unfriendly when fresh because it gives off Sulphur Dioxide, and in the presence of water Hydrogen Sulphide (rotten egg smell) and Sulphuric acid are generated. These are at least a nuisance and at worst potentially dangerous. Fortunately the material stabilises rapidly when cooled, and the potential for obnoxious leachate diminishes very rapidly after the 'first flush'. However, the 
generation of sulphuric acid causes considerable corrosion damage in the vicinity of Blast Furnaces. The dry granulation process eliminates $\mathrm{H} 2 \mathrm{~S}$ and significantly reduces sulphur gas emissions, furthermore the leachability of sulphur and other compounds is also reduced due to the glassy nature of the product.

The product quality is as follows:

- $\quad+95 \%$ Glass content across full size spectrum $(1-6 \mathrm{~mm})$ with very low porosity (see Figs. 5 and 6).

- Loss on Ignition $<0.1 \%$.

- Average particle size is 1 to $3 \mathrm{~mm}$. This is dependent on cup speed and slag properties (see Table 1 below showing typical sieve sizing analysis).

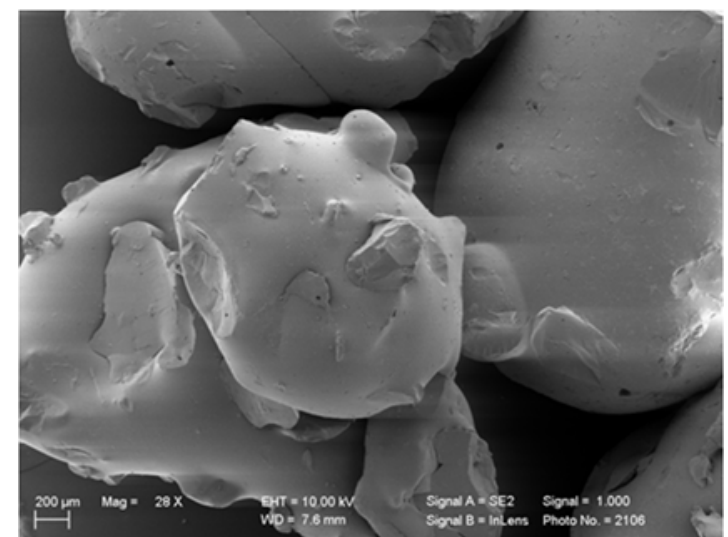

Figure 6. Microscopic (x25) view of granule $<3 \mathrm{~mm}$ Showing low porosity of grain.

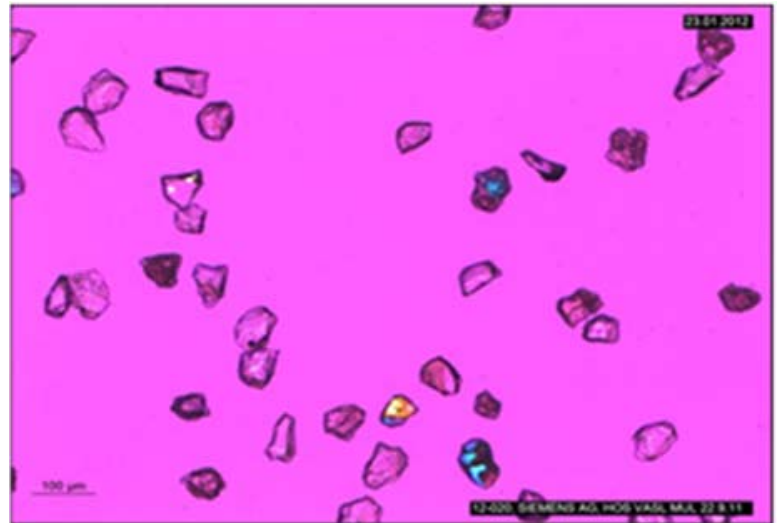

Figure 7. Slag Analysis showing glassy structure when ground to $40-60$ micron.

Table 1. Average particle size of the dry granulate

\begin{tabular}{|c||c|c|}
\hline $\begin{array}{c}\text { particle size } \\
{[\mathrm{mm}]}\end{array}$ & $\begin{array}{c}\text { mass } \\
{[\%]}\end{array}$ & $\begin{array}{c}\text { accumulated } \\
{[\%]}\end{array}$ \\
\hline $0-1$ & 7,02 & 7,02 \\
$1-2$ & 39,64 & 46,65 \\
$2-3$ & 33,36 & 80,02 \\
$3-4$ & 16,11 & 96,13 \\
\hline $4-6,3$ & 3,87 & 100,00 \\
\hline sum & 100 & \\
\hline
\end{tabular}




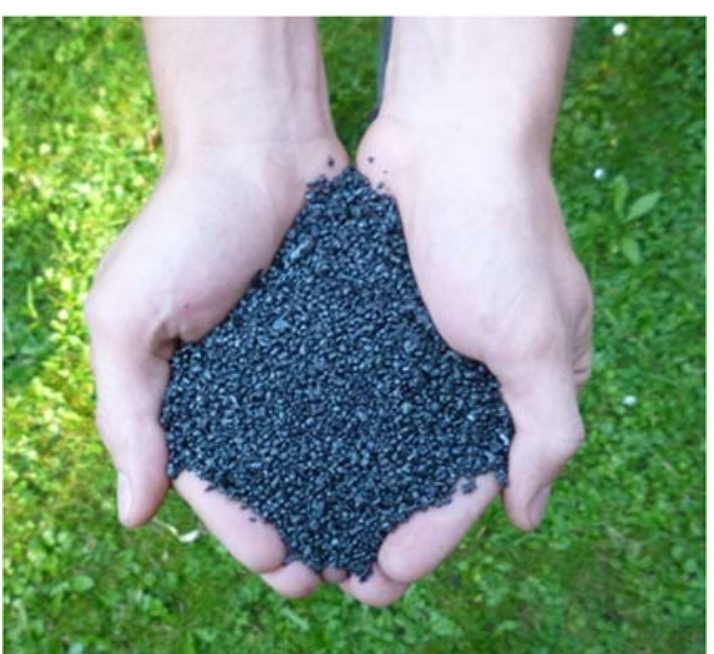

Figure 8. Dry granulated slag recently produced at Leoben.

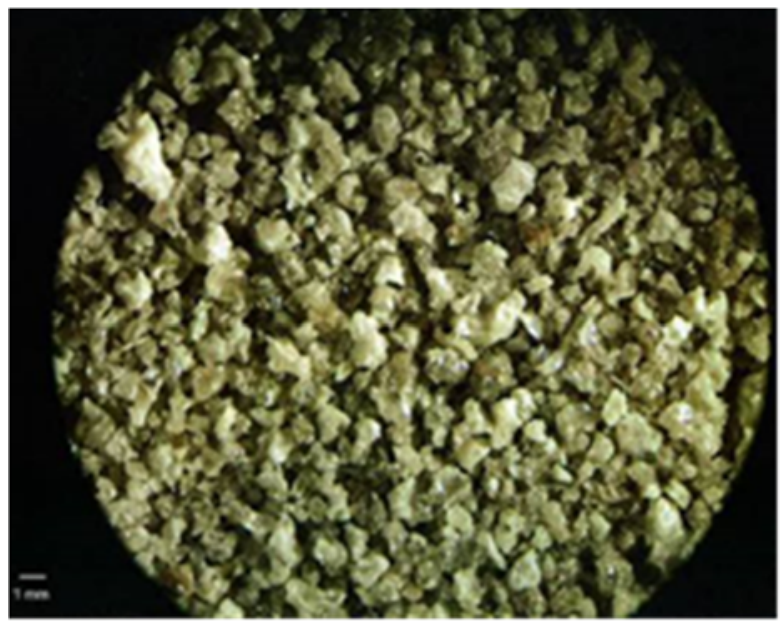

Figure 9. A typical wet granulated slag.

In addition, since slag granulate is to be used as feedstock for the cement industry, the following parameters are also important:

Grinding energy required to reduce granules from $3 \mathrm{~mm}$ to reach $4000 \mathrm{~cm} 2 / \mathrm{g}$ (blaine) $=70 \mathrm{Kwh} / \mathrm{t}$.

Table 2 showing relative block crushing strength of OPC and OPC/DSG mixture. It can be seen here, the relative block crushing strength of $100 \%$ ordinary Portland cement when compared with a mix with $50 \%$ of the OPC is substituted with ground material from blast furnace slag that has been made using the dry granulation method.

Table 2. Block crushing strength of OPC and OPC/DSG mixture

\begin{tabular}{|c|c|c|}
\hline \multirow{2}{*}{$\begin{array}{c}\text { Curing Time } \\
\text { (Days) }\end{array}$} & \multicolumn{2}{|c|}{ Block Crushing Strength (N/mm2) } \\
\cline { 2 - 3 } & $100 \%$ OPC $^{*}$ & $\begin{array}{c}50 \% \text { OPC / 50\% } \\
\text { DSG }\end{array}$ \\
\hline & 34.3 & 15.6 \\
2 & 49.5 & 34.1 \\
28 & 59.6 & 57.2 \\
91 & 66.1 & 69.2 \\
\hline Notes & \multicolumn{2}{|c|}{ OPC - Ordinary Portland Cement } \\
& DSG - Dry Granulated Slag \\
\hline
\end{tabular}

The temperatures achieved in the technical granulation plant indicated that the target temperature of between 400 and 650 degrees centigrade necessary for commercial heat recovery is certainly achievable on the small scale (see Figure 9).

Calculations for a full scale plant based upon a CFD model which has been calibrated using data from the technical scale plant show figures toward the maximum target figure are also achievable. 


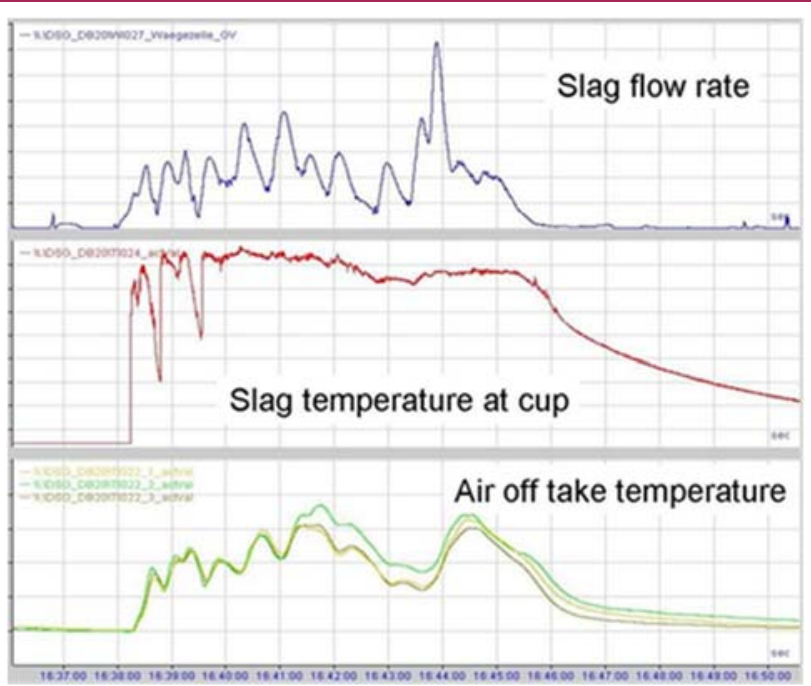

Figure 10. Typical Leoben Data Collection.

\section{HEAT RECOVERY DEVELOPMENTS}

One of the main goals for the current dry slag granulation technology development was the recovery of the large thermal energy potential of the slag. By cooling the granulator with air the off gas can be used for driving different heat recovery applications. Several systems capable of utilising the energy in hot air delivered from the granulator have been considered. The major challenge is the intermittent availability of molten slag.

For efficient heat recovery systems high temperatures of the off gas are required, so the aim is to produce off gas temperatures at $\sim 600^{\circ} \mathrm{C}$ at the industrial sized plants (previous research results already show promising temperatures). By tuning the cooling air distribution this could be increased significantly, perhaps to $650^{\circ} \mathrm{C}$. With the control of the cooling air amount in dependency on current slag flow the off gas temperature can be kept at a constant level for almost every load condition.

Depending on the plant setup the energy can be used directly for preheating or heating purposes in the core process, or for the production of process steam and/or electricity. Generally the most common application for heat recovery is the production of process steam that can be used within the steelworks - feeding of steam in existing steelwork steam grid or replacement of fired steam boilers at steam consumers. The granulator off gas will be guided into waste heat boiler(s) for steam production. Because of the high granulator off gas temperatures superheated steam of a high quality can be produced together with good thermal efficiency of the boiler. The boiler off gas can be partly recirculated to the granulator to create an even higher total process energy efficiency.

In (Figure 11) the process flow diagram of a granulator and heat recovery system for superheated steam production is shown. The process parameters shown in this figure are exemplary for a slag flow of $1 \mathrm{t} / \mathrm{min}$ which gives an output of approx. $29 \mathrm{t} / \mathrm{h}$ superheated steam. Converting this amount of produced steam in a steam turbine and generator means an electricity output potential of approximately 6,5 MWel (for 1 t/min slag flow). 


\section{5th Ironmaking \\ 16th Iron Ore \\ 3rd Agglomeration}

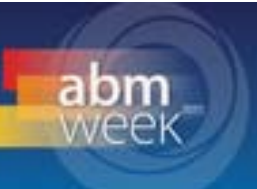

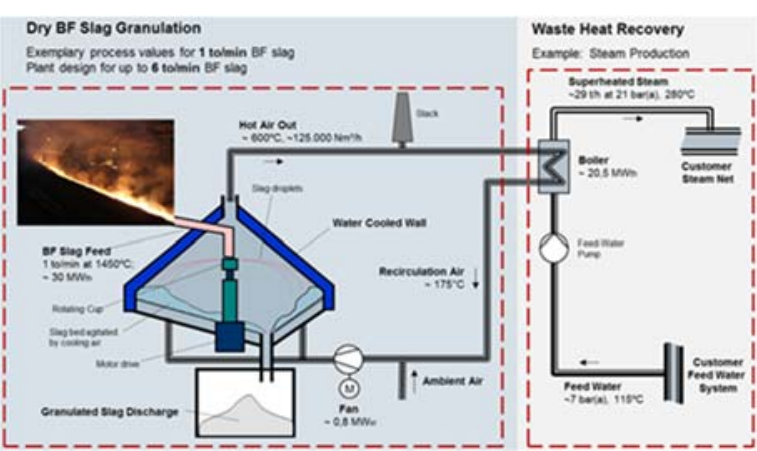

Figure 11. Process flow diagram of a dry slag granulation system with heat recovery system for steam production.

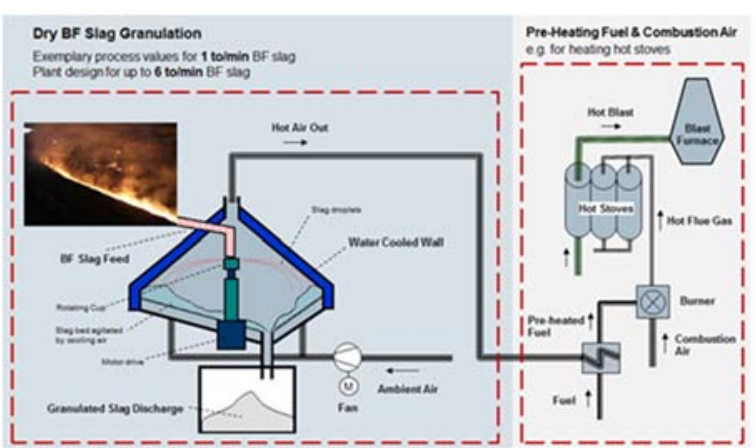

Figure 12. Process flow diagram of a dry slag granulation system with heat recovery system for fuel preheating.

\section{CONCLUSION}

Liquid Blast Furnace slag represents one of the largest high temperature reserves of waste energy in the steel industry that is still not utilized.

Through research and ongoing progress with our industrial partners, Primetals Technologies is dedicated to reaching the first viable solution for heat recovery from Blast Furnace slag on an industrial scale.

The prospect of waste heat recovery and a cleaner ecological footprint are clear benefits for the Ironmaker.

The additional advantage to the cement manufacturer of receiving a first class product which is dry, glassy and easy to handle makes this a very good fit with our overall customers needs.

Dry Slag Granulation with Heat Recovery stands as one of our very top Research and Development programs to deliver a customer focused, value added solution.

The next phase of building an industrial scale plant will be realized in 2016 with an industrial partner.

\section{The summary advantages of the Dry Slag Granulation are:}

- Heat recovery is possible due to the prolonged higher process temperature

- The unit can handle the full slag flow rate direct from a Blast Furnace

- High grade granulate that is suitable for use in the cement industry

- Potentially lower capital cost than an equivalent wet system

- Potentially lower operating and maintenance costs than an equivalent wet system

- $\quad$ Elimination of water systems

- No ground water contamination

- Handle able product

- No downstream drying costs

- No steam emissions and associated visibility, environmental and corrosion problems

- Significantly lower sulphur emissions. 